\title{
Research on the separation properties of empty-column gas chromatography (EC-GC) and conditions for simulated distillation (SIMDIS)
}

\author{
Grzegorz Boczkaj • Marian Kamiński
}

Received: 2 May 2013 / Revised: 5 July 2013 / Accepted: 9 July 2013 / Published online: 8 August 2013

(C) The Author(s) 2013. This article is published with open access at Springerlink.com

\begin{abstract}
Previous studies have revealed it is possible to separate a high-boiling mixture by gas chromatography in empty fused-silica capillary tubing rather than in columns coated with stationary phase. Chromatographic separation occurs solely on the basis of the different boiling points of the substances separated. The high similarity of such separations to those in classic distillation seems advantageous when gas chromatography is used for simulated distillation. This paper presents results from further research on the separation properties of empty fused silica tubing. The efficiency of this chromatographic system has been examined. The usefulness of such conditions has been studied for simulated distillation, i.e. to determine the boiling-point distribution of complex mixtures, mainly petroleum fractions and products, on the basis of their retention relative to reference substances. The results obtained by use of emptycolumn gas chromatography (EC-GC) and by use of classical simulated distillation columns have been compared for solutes of different polarity. Studies revealed boiling points determined by EC-GC were more accurate than those obtained by the standard method of simulated distillation.
\end{abstract}

Keywords Simulated distillation · SIMDIS · EC-GC · Chromatographic separation $\cdot$ Fuels $\cdot$ GC

Electronic supplementary material The online version of this article (doi:10.1007/s00216-013-7236-z) contains supplementary material, which is available to authorized users.

G. Boczkaj $(\square) \cdot$ M. Kamiński

Chemical Faculty, Department of Chemical and Process

Engineering, Gdansk University of Technology, G. Narutowicza

11/12 Str., 80-233 Gdansk, Poland

e-mail: grzegorz.boczkaj@gmail.com

\section{Introduction}

Progress in separation techniques, especially chromatography, has led to significant shortening of the time required to achieve satisfactory separation of the components of mixtures. In gas chromatography, separation is achieved by use of capillary columns the inner diameter and the film thickness of which have decreased with progress in column manufacture. For decades, the most widely used column internal diameters (ID) were 320 and $250 \mu \mathrm{m}$ and the film thickness ranged from 0.1 to $1 \mu \mathrm{m}$. So-called fast GC with columns of ID $100 \mu \mathrm{m}$ (and less) is becoming a promising approach. When hydrogen is used as carrier gas, separation efficiency decreases only slightly with large increases in carrier gas velocity. This results in ultra-high-performance chromatographic systems $[1,2]$.

At the other extreme of users' expectations of chromatographic equipment are applications in which sample capacity and the temperature resistance of the stationary phase are much more important than expected resolution of the chromatographic system, which is reduced to an absolute minimum. One such application is simulated distillation [3, 4], in which resolution must ensure separation of selected $n$-alkanes only (a few or several standards in a boiling point range covering the range of samples analyzed), which are used for calibration of the method [5,6]. Achieving separation of a mixture of standards which differ in boiling point by tens of degrees Celsius by use of capillary gas chromatography does not cause any problems. Much more important is the linearity of retention time-boiling point dependence, relative to $n$-alkanes, for the other groups of chemical substances present in the sample.

The most important use of simulated distillation is determination of the distillation characteristics of petroleum fractions and products [7-10]. The composition of samples of gasoline, diesel fuel, or vacuum distillates is very rich [11]. To properly determine the distillation curve by simulated 
distillation, the relationship between boiling point and retention time for substances other than the $n$-alkanes must be similar to, and preferably identical with, that for the $n$-alkanes under the separation conditions used. If retention of the sample components deviates substantially from that expected, errors will occur in the distillation curve $[12,13]$. More detailed analysis of the problems which occur in simulated distillation is available elsewhere [14, 15].

Research performed to optimize the conditions used for the analysis revealed it is possible to replace a capillary column containing a thick film of stationary phase with empty deactivated fused-silica capillary tubing. Such separation conditions were defined as empty-column gas chromatography (EC-GC) [15]. Because of elimination of the sorption interactions, EC-GC seems to "simulate" the distillation process much better, and thus provide more consistent results. However, the lack of the stationary phase in EC-GC results in significant reduction of the separation efficiency. As can be seen from the multiannual comparative studies of the ASTM, achievement of full compliance between results obtained by classical distillation and SIMDIS is not possible, because of the low efficiency of classical distillation [5]. Agreement of results with those obtained by use of classical distillation is achieved by use of a column with an efficiency of approximately 15 theoretical plates (ASTM 2892) [16]. From this perspective, use of EC-GC (loss of performance) should have a positive effect on better "simulation" of classical distillation according to ASTM D86.

This paper presents the results of further research on ECGC conditions. We constructed efficiency plots describing the relationship between efficiency and carrier gas velocity and compared the accuracy of true boiling points (TBP) determined for selected compounds by use of SIMDIS and EC-GC conditions.

\section{Material and methods}

Materials

- Standard mixture for SIMDIS 2887 Extended- $n$-alkanes in the range $n-\mathrm{C}_{5}-n-\mathrm{C}_{60}$ (AC Analytical Controls);

- Standards: 1-methylnaphthalene, 4-nitroaniline, 2,4dinitroaniline, benzidine, dibenzothiophene, diethyl sulfone, pyrene, chrysene, anthracene, phenanthrene, menthol, squalane, 4,6-dinitro-o-cresol, 1-naphthylamine, 9hydroxyfluorene, 1,10-phenanthroline, naphthalene, 1naphthol, 2-naphthol, 4-methyldibenzothiophene, 4,6dimethyldibenzothiophene, dinonyl phthalate, triphenylphosphine sulfide, 2,6-dichlorophenol, 2,4-dinitrophenol, indophenol, 1-undecanol, acridine, 8-hydro xyquinoline, palmitic acid, 1,6-hexanediol, (Sigma-
Aldrich, USA), 4-aminopyridine, 2,4,6-trimethylpyridine, (Loba Chemie, Austria);

- Gas standard mixture of methane in air (dead time marker) (100 ppm, Linde Gas);

- Carbon disulfide (>99\% (GC), Fluka Analytical), methanol (HPLC purity, Merck); and

- Nitrogen, helium, air; 5.0 N purity (Linde Gas).

Instruments

- Hydrogen generator (Packard, USA) SIMDIS

- Gas chromatograph Autosystem (Perkin Elmer, USA) with software for data acquisition TotalChrom ver. 6.3 (Perkin Elmer)

\section{EC-GC}

- Gas chromatograph Autosystem XL (Perkin Elmer, USA) with software for data acquisition TotalChrom ver. 6.3 (Perkin Elmer).

Methods

Preparation of solutions

A solution of $n$-alkane standards was prepared by dissolving a weighed sample in carbon disulfide at a weight ratio of 1:100. Squalane solution of concentration $100 \mathrm{ppm}(\mathrm{m} / \mathrm{m})$ was prepared in carbon disulfide. Standard solutions of other substances at concentrations of approximately $100 \mathrm{ppm}$ were prepared, as far as possible, in carbon disulfide. Solutions of reference substances insoluble in $\mathrm{CS}_{2}$ were prepared at a concentration of approximately $100 \mathrm{ppm}$ in methanol.

\section{Chromatographic conditions}

Samples $(1 \mu \mathrm{L})$ were injected manually in splitless mode by use of a microsyringe. Each sample was chromatographed three times.

\section{SIMDIS}

- Carrier gas: nitrogen, $10 \mathrm{~mL} \mathrm{~min}^{-1}$;

- Column: Zebron ZB-1XT SIMDIS (Phenomenex) $10 \mathrm{~m} \times 0.53 \mathrm{~mm} \times 0.15 \mu \mathrm{m}$;

- Temperature program: $40^{\circ} \mathrm{C}(1 \mathrm{~min})$, ramp $5^{\circ} \mathrm{min}^{-1}$ to $380^{\circ} \mathrm{C}(20 \mathrm{~min})$;

- Split/splitless injector in splitless mode, temperature $380^{\circ} \mathrm{C}$; and

- Flame ionization detector (FID), temperature $385^{\circ} \mathrm{C}$.

\section{EC-GC}


- Column: empty fused silica tubing with methyl-deactivated inner surface, $30 \mathrm{~m} \times 0.53 \mathrm{~mm}$ (BGB Analytic, Switzerland). Other conditions were as described for SIMDIS.

\section{Determination of the Van Deemter plots for EC-GC conditions}

Van Deemter plots were determined for squalane. Analysis was performed in constant-flow mode with three carrier gases - nitrogen, helium, and hydrogen. For each condition three separate runs were performed.

\section{Studies on the accuracy of boiling point determination under SIMDIS and EC-GC conditions}

Boiling points determined by use of SIMDIS and EC-GC conditions were calculated on the basis of the retention time of the solute, using $n$-alkanes for calibration. The boiling point was calculated on the basis of interpolation from two neighbouring $n$-alkanes. The TBP values used were obtained from the literature.

\section{Results and discussion}

Use of EC-GC conditions, i.e. the absence of the stationary phase in the column, enables maximum reduction of sorption effects during the separation. This results in greater similarity of the conditions used for separation by gas chromatography and for classic distillation. This effect was examined in this work by comparing boiling points determined for selected chemicals by SIMDIS and EC-GC with the true (actual) boiling point (TBP). In this study a "classic" 10-m column was used for SIMDIS and an empty column with a deactivated inner surface was used for EC-GC. Previous studies revealed that use of an empty $30-\mathrm{m}$ column enables satisfactory separation of the $n$-alkane standards used for calibration of the method [15]. Comparison of the accuracy of boiling point determination for columns of the same length would not be practical or expedient, because the retention relative to that of $n$-alkanes (retention index) is not dependent on column length. Use of a 10-m column for EC-GC does not provide adequate resolution, whereas application of 30-m SIMDIS column unreasonably lengthens the time required for analysis of high-boiling fractions. The EC-GC conditions provide the same reproducibility of results compared with classic SIMDIS. The retention times obtained in this work differed by no less than $2 \mathrm{~s}$ for triplicate injection, which is typical of reproducibility for manual sample injection.
Efficiency of the chromatographic system under EC-GC conditions

The lack of the stationary phase in the column results in significant reduction of column resolution. This happens, in particular, because of the much lower efficiency of a column without stationary phase. Fig. 1 shows the Van Deemter plots obtained for the three typical carrier gases used in gas chromatography-helium, hydrogen, and nitrogen (for data points please refer to Electronic Supplementary Material Table S1).

Separation effect and usefulness of EC-GC conditions for the simulated distillation of high-boiling mixtures have been described elsewhere [15]. Van Deemter plots were determined for 2,6,10,15,19,23-hexamethyltetracosane $\left(\mathrm{C}_{30} \mathrm{H}_{62}\right.$, boiling point $470{ }^{\circ} \mathrm{C}$, squalane). This compound is still used as a non-polar stationary phase for gas-liquid chromatography. Use of EC-GC enables its complete elution from the chromatographic column at a temperature not exceeding $145^{\circ} \mathrm{C}$. The physicochemical properties of this compound are similar to those of the petroleum factions and products analyzed by SIMDIS; it is, therefore, suitable for determination of column efficiency in EC-GC. The results showed that the characteristics of changes in efficiency, expressed as the dependence of the height equivalent to a theoretical plate (HETP) on average flow velocity of the mobile phase $(u)$, are similar to those reported for classical columns containing stationary phase. The flow velocities resulting in the highest efficiency were $12.5 \mathrm{~cm} \mathrm{~s}^{-1}$ for nitrogen, $17.0 \mathrm{~cm} \mathrm{~s}^{-1}$ for helium, and $23.4 \mathrm{~cm} \mathrm{~s}^{-1}$ for hydrogen. Under these conditions, the efficiency of the $30 \mathrm{~m}$ column was 3906 theoretical plates for helium, 4155 for hydrogen, and 4112 for nitrogen. Although this separation efficiency is not high compared with standard GC capillary columns, it is adequate for simulated distillation. In classic simulated distillation on the 10.0-m column used in this work the efficiency was approximately 20,000 theoretical plates (approx. 2000 plates per meter).

Comparison of the efficiency curves obtained under ECGC conditions with "typical" results obtained for GC capillary columns reveals that the effect of carrier gas flow velocity changes in EC-GC is much smaller. Up to $50 \mathrm{~cm} \mathrm{~s}^{-1}$ there was no significant decrease in efficiency for any of the three carrier gases tested. Comparison of the different mobile phases showed that the largest effect of flow velocity on the efficiency is observed for nitrogen, and the lowest was observed for hydrogen, which is a well known phenomenon in GC. Much lower efficiency of EC-GC results from the extremely low "capacity" of the column-sorption occurs on the surface of the deactivated column only and results from distribution of the analyte between the gas and condensed phases. The partition coefficient in this case is dependent solely on the vapour pressure of a substance at a given 
Fig. 1 Comparison of the Van Deemter plots for three carrier gases for a $0.53 \mathrm{~mm}$ ID capillary column

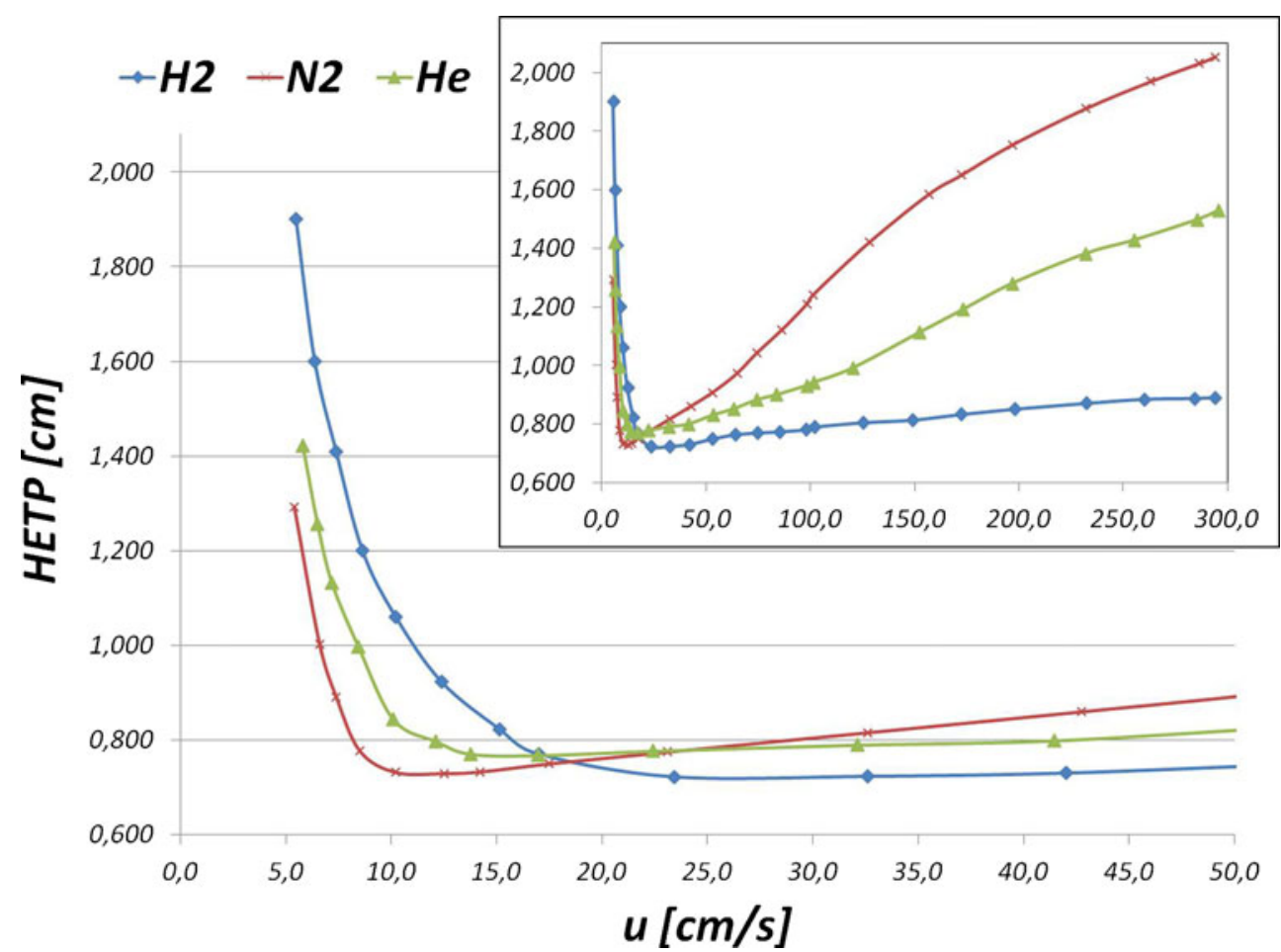

temperature. The disadvantage of such low capacity is, however, a severe tailing of the chromatographic peaks - examples of the peak shapes are presented in Electronic Supplementary Material Fig. S1.

Comparison of the accuracy of boiling points determined under EC-GC and SIMDIS conditions

The largest advantage of EC-GC seems to be the greater similarity compared with classical SIMDIS of the phenomena occurring during chromatographic separation to those occurring during classical distillation. Research on compounds of different polarity which may be present in the analyzed mixtures revealed significant differences between boiling points determined by SIMDIS and the true values [5, 13].

The results obtained revealed that for every compound tested the boiling point determined under EC-GC conditions is closer to the real value than that determined by use of conventional simulated distillation. The greatest accuracy in EC-GC was obtained for dinonyl phthalate, menthol, and 1naphthol (Table 1). Deviations from the real values were zero or one degree Celsius. Under SIMDIS conditions the best agreement was obtained for squalane (5 Celsius degrees). Especially important is the improvement of distillation temperature determination for aromatic compounds, including substances containing sulfur and nitrogen heteroatoms. Because of their occurrence in fractions and petroleum products, correct "simulation" of the distillation characteristics of these groups of substances significantly increases the accuracy of the boiling point distribution determined by simulated distillation. Calibration data for EC-GC and SIMDIS are listed in Electronic Supplementary Material Table S2.

The method involving use of an empty fused-silica capillary with a deactivated inner surface should be used mainly for determination of the boiling point distribution of medium and low-volatility mixtures, which can contain significant amounts of polar chemicals and the products obtained from treatment processes. Because of the better simulation of the distillation characteristics of each of the group of compounds tested, including aromatic hydrocarbons and polar chemicals, it seems to be a good method for study of the boiling point distribution of the products from processes such as pyrolysis and catalytic pyrolysis. Current research trends and perspectives in the recovery of thermal energy and fuel liquid fractions from solid waste increases the significance of methods which enable accurate determination of the distillation characteristics of mixtures containing significant concentrations of polar components.

\section{Conclusions}

The efficiency of separation under EC-GC conditions has been studied in the work discussed in this paper. For a 30meter column of diameter $0.53 \mathrm{~mm}$, efficiency of 130-140 theoretical plates per meter was obtained. Previous studies have shown that the separation efficiency obtained under EC-GC conditions meets the requirements for the simulated 
Table 1 Comparison of the results from determination of boiling points under SIMDIS and EC-GC conditions

\begin{tabular}{|c|c|c|c|c|c|}
\hline \multirow[t]{2}{*}{ Chemical compound } & \multirow{2}{*}{$\begin{array}{l}\text { True boiling } \\
\text { point }(\mathrm{TBP}) \\
\left({ }^{\circ} \mathrm{C} ; \mathrm{P}=760\right. \\
\mathrm{mm} \mathrm{Hg})\end{array}$} & \multicolumn{2}{|l|}{ SIMDIS } & \multicolumn{2}{|l|}{ EC-GC } \\
\hline & & $\begin{array}{l}\text { Calculated boiling } \\
\text { point }\left({ }^{\circ} \mathrm{C}\right)\end{array}$ & $\begin{array}{l}\text { Difference } \\
\left({ }^{\circ} \mathrm{C}\right)\end{array}$ & $\begin{array}{l}\text { Calculated boiling } \\
\text { point }\left({ }^{\circ} \mathrm{C}\right)\end{array}$ & $\begin{array}{l}\text { Difference } \\
\left({ }^{\circ} \mathrm{C}\right)\end{array}$ \\
\hline Diethyl sulfone & 246 & 335 & -89 & 302 & -56 \\
\hline 1,10-Phenanthroline & 360 & 338 & 22 & 378 & -18 \\
\hline Benzidine & 401 & 360 & 41 & 411 & -10 \\
\hline Dinonyl phthalate & 413 & 407 & 6 & 413 & 0 \\
\hline Menthol & 212 & 218 & -6 & 211 & 1 \\
\hline 1-Naphthol & 278 & 265 & 13 & 277 & 1 \\
\hline 2,4-Dinitroaniline & 401 & 404 & -3 & 399 & 2 \\
\hline 2-Naphthol & 285 & 271 & 14 & 283 & 2 \\
\hline 2,4,6-Trimethylpyridine & 171 & 164 & 7 & 168 & 3 \\
\hline 2,4-Dinitrophenol & 312 & 303 & 9 & 308 & 4 \\
\hline Squalane & 470 & 465 & 5 & 466 & 4 \\
\hline 2,6-Dichlorophenol & 219 & 207 & 12 & 214 & 5 \\
\hline 1-Undecanol & 243 & 229 & 14 & 238 & 5 \\
\hline Acridine & 346 & 317 & 29 & 341 & 5 \\
\hline Naphthalene & 218 & 202 & 16 & 213 & 5 \\
\hline 4-Nitroaniline & 332 & 314 & 18 & 326 & 6 \\
\hline 4-Aminopyridine & 273 & 256 & 17 & 267 & 6 \\
\hline Indophenol & 360 & 332 & 28 & 354 & 6 \\
\hline 1,6-Hexanediol & 208 & 199 & 9 & 200 & 8 \\
\hline 8-Hydroxyquinoline & 276 & 253 & 23 & 267 & 9 \\
\hline 1-Methylnaphthalene & 234 & 223 & 11 & 224 & 10 \\
\hline Palmitic acid & 352 & 330 & 22 & 339 & 13 \\
\hline Dibenzothiophene & 332 & 297 & 35 & 317 & 15 \\
\hline 4-Methyldibenzothiophene & 349 & 312 & 37 & 334 & 15 \\
\hline 4,6-Dinitro- $O$-cresol & 332 & 308 & 24 & 317 & 15 \\
\hline 4,6-Dimethyldibenzothiophene & 365 & 329 & 36 & 349 & 16 \\
\hline 9-Hydroxyfluorene & 368 & 344 & 24 & 350 & 18 \\
\hline 1-Naphthylamine & 301 & 259 & 42 & 281 & 20 \\
\hline Anthracene & 342 & 305 & 37 & 320 & 22 \\
\hline Phenanthrene & 332 & 304 & 28 & 309 & 23 \\
\hline Triphenylphosphine sulfide & 429 & 392 & 37 & 405 & 24 \\
\hline Pyrene & 395 & 345 & 50 & 359 & 36 \\
\hline Chrysene & 447 & 376 & 71 & 407 & 40 \\
\hline
\end{tabular}

distillation (SIMDIS) and enables complete separation of a standard mixture of $n$-alkanes [15].

EC columns similar to those described in this paper are used in our laboratory for routine analysis of boiling point distribution - mainly for distillates from vacuum distillation. During more than two years of using such columns (several times a week) we have not encountered any symptoms of degradation, for example lower resolution or retention time shifts of the $n$-alkane standards. We replace only the silanized wool in the liner. This is done routinely when a septum in the injector needs to be replaced (approximately every 100 runs).
The studies also revealed that EC-GC conditions enable better simulation of distillation which results in greater similarity of the distillation characteristics determined for each of the groups of compounds studied. The biggest advantage of EC-GC conditions is much better determination of distillation characteristics for polar substances. This is especially important for complex mixtures for which the boiling point distribution is determined by SIMDIS. Simulated distillation is now increasingly used in research on the pyrolysis and liquefaction of solid and semi-solid wastes. Because the products of these processes contain large amounts of aromatic hydrocarbons, correct determination of the boiling point 
range of this group of substances is crucial to obtaining the correct results by simulated distillation. Application of EC-GC conditions to such materials seems to be the optimum solution.

Acknowledgements The authors would like to thank the National Science Centre for financial support (grant no. UMO-2011/01/N/ST8/07757).

Open Access This article is distributed under the terms of the Creative Commons Attribution License which permits any use, distribution, and reproduction in any medium, provided the original author(s) and the source are credited.

\section{References}

1. Mastovská K, Lehotay SJ (2003) Practical approaches to fast gas chromatography-mass spectrometry. J Chromatogr A 1000:153-180

2. Tranchida PQ, Mondello L (2012) Current-day employment of the micro-bore open-tubular capillary column in the gas chromatography field. J Chromatogr A 1261:23-36

3. Green LE, Schumauch LJ, Worman JC (1964) Simulated distillation by Gas chromatography. Anal Chem 36:1512-1516

4. Worman JC, Green LE (1965) Simulated distillation of high boiling petroleum fractions. Anal Chem 37:1620-1621

5. ASTM D2887: Standard test method for boiling range distribution of petroleum fractions by gas chromatography

6. ASTM D3710: Test method for boiling range distribution of gasoline and gasoline fractions by gas chromatography
7. ASTM D5307: Standard test method for determination of boiling range distribution of crude petroleum by gas chromatography

8. ASTM D6352: Standard test method for boiling range distribution of petroleum distillates in boiling range from 174 to $700^{\circ} \mathrm{C}$ by gas chromatography

9. ASTM D7169: Standard test method for boiling point distribution of samples with residues such as crude oils and atmospheric and vacuum residues by high temperature gas chromatography

10. ASTM D7213: Standard test method for boiling range distribution of petroleum distillates in the boiling range from 100 to $615^{\circ} \mathrm{C}$ by gas chromatography

11. Darka WA (1982) Crude Oil hydrocarbon group separation quantitation. J Liquid Chromatogr 5:1645-1652

12. Roussis SG, Fitzgerald WP (2000) Gas chromatographic simulated distillation-mass spectrometry for the determination of the boiling point distributions of crude oils. Anal Chem 72:1400-1409

13. Durand JP, Bré A, Béboulène JJ, Ducrozet A, Carbonneaux S (1999) Improvement of simulated distillation methods by gas chromatography in routine analysis. Oil Gas Sci Technol Rev IFP $54: 431-438$

14. Boczkaj G, Kamiński M (2010) Wykorzystanie chromatografii gazowej do destylacji symulowanej (SIMDIS). Aktualny stan wiedzy i nowe perspektywy (Gas Chromatography for simulated distillation. State of the art and perspectives). Camera Separatoria 2:89-99

15. Boczkaj G, Przyjazny A, Kamiński M (2011) New procedure for the determination of distillation temperature distribution of highboiling petroleum products and fractions. Anal Bioanal Chem 399:3253-3260

16. ASTM D2892: Test method for distillation of crude petroleum (15Theoretical Plate Column); 